\title{
Lack of data on standardized metrics for surgical care in a developing country with middle total expenditure on health
}

\author{
Carlos Javier Shiraishi Zapata, MD
}

Received: 24 January 2016/Revised: 5 February 2016/Accepted: 17 February 2016/Published online: 22 February 2016

(C) Canadian Anesthesiologists' Society 2016

\section{To the Editor,}

I read with great interest the recent editorial by Dr. Weiser et al. ${ }^{1}$ that referred to an accompanying report describing research on avoidable perioperative mortality in Zambia. $^{2}$ They emphasized the need to measure the results of health care delivered, especially when reporting on populations undergoing various types of surgical procedures.

The lack of data on the recommended measures to evaluate national surgical services is a disturbing reality worldwide. As many as $70 \%$ of countries have no information on the number of surgeries performed, and virtually none of them attempts to assess the distribution of surgical resources or results. ${ }^{3}$ This deficit, however, is not limited to countries with poor and low total expenditure on health per capita. Some countries of medium total expenditure on health per capita, such as Peru, also lack this information.

Peru, with a total expenditure on health per capita of $\$ 626$ USD in $2013,{ }^{4}$ has no data on measures to assess the level of surgical services across the country. This situation is evidenced by the National Statistics Institute of Peru-a governmental organization dedicated to the production of official statistics on various parameters (including health indicators) - which has no national data on any of these measures (e.g., number of surgeries, operating rooms, accredited surgeons and anesthesiologists, postoperative same-day or 30-day mortality rate) for any period of time. These gaps in health care statistics exist even though the technical standard for anesthesiology services, which came

C. J. Shiraishi Zapata, MD (ه)

Servicio de Centro Quirúrgico y Anestesiología, Hospital

ESSALUD Talara, Piura, Peru

e-mail: shiraishi52@hotmail.com into force in 2005, obliges all Peruvian surgical centers (i.e., public, private, mixed) to report rates and indicators on the surgery performed. ${ }^{5}$

Indeed, Peru has data from only one segment of the population - patients who received health care in the Social Health Insurance-ESSALUD Peru system, a public institution with a registered population of $10,285,389$ from an estimated Peruvian total population of 30,475,144 in 2013. ${ }^{6}$ During the same period, 236,828 surgical procedures were performed in the subgroup of insured population attached to Social Health Insurance hospitals that provide care of greater complexity and response capacity (population 7,246,154). ${ }^{7}$ These data resulted in a rate of 3268 surgeries per 100,000 inhabitants during 2013, a figure that is consistent with the average rate of surgery estimated worldwide in 2012, which was 4,822 surgeries (95\% confidence interval, 3,085 to 6,560 ) per 100,000 inhabitants in the group of countries with medium total expenditure on health per capita. ${ }^{8}$ Nonetheless, the surgical data of the remainder of the aforementioned insured people $(3,039,235$ inhabitants) was not published by the institution. In addition, the same information for the rest of the Peruvian population $(20,189,755$ inhabitants) was totally unknown during that period.

The pending governments' task of countries that lack these measures, is to implement urgently the collection of national data regarding surveillance measures of surgical care for their populations. This has been detailed in Resolution WHA68.15 of the World Health Organization, which addressed the strengthening of essential surgical and emergency care and anesthesia as components of universal health coverage. The implementation of gathering this information, as clearly mentioned by the authors, should help us to understand what has been done, detect any faults in the system, and make improvements in the health system 
of a country. It would eventually lead to providing better quality health care to a country's citizens.

Conflicts of interest None declared.

\section{References}

1. Weiser TG, Makasa EM, Gelb AW. Improving perioperative outcomes in low-resource countries: It cańt be fixed without data. Can J Anesth 2015; 62: 1239-43.

2. Lillie EM, Holmes CJ, ÓDonohoe EA, et al. Avoidable perioperative mortality at the University Teaching Hospital, Lusaka, Zambia: a retrospective cohort study. Can J Anesth 2015; 62: 1259-67.

3. Weiser TG, Makary MA, Haynes AB, Dziekan G, Berry WR. Gawande AA; Safe Surgery Saves Lives Measurement and Study Groups. Standardised metrics for global surgical surveillance. Lancet 2009; 374: 1113-7.

4. World Health Organization. Geneva: World Health Organization; 2005. Global Health Observatory Data Repository. "Health expenditure per capita, by country, 1995-2013. Peru. Available from URL: http://apps.who.int/gho/data/view.main.HEALTHEXP CAPPER?lang=en (accessed February 2016).

5. Ministerio de Salud del Perú. Lima: Oficina General de Comunicaciones del Ministerio de Salud del Perú; 1997. Sección de Normas Legales. RM 486-2005:" Norma Técnica de los Servicios de Anestesiología". Available from URL: ftp://ftp2. minsa.gob.pe/normaslegales/2005/RM486_2005_MINSA_ok.pdf (accessed February 2016).

6. Instituto Nacional de Estadística e Informática. Lima: Oficina Técnica de Informática; 1997 Sección de Estadísticas: población y vivienda. Available from URL: https://www.inei.gob. pe/estadisticas/indice-tematico/poblacion-y-vivienda/ (accessed February 2016).

7. Seguro Social de Salud del Perú-ESSALUD. Lima: Oficina de Relaciones Institucionales; 2001. Memoria Anual 2013 del Seguro Social de Salud-ESSALUD. Available from URL: http://www. essalud.gob.pe/transparencia/pdf/memoria/memoria_2013.pdf (accessed February 2016).

8. Weiser TG, Haynes AB, Molina $G$, et al. Estimate of the global volume of surgery in 2012: an assessment supporting improved health outcomes. Lancet 2015; 385(Suppl 2): S11. 